\title{
puente de acceso principal
}

\author{
$560-20$
}

Consta de nueve vanos con luces comprendidas entre $11 \mathrm{~m}$ y $17 \mathrm{~m}$.

Los cinco vanos centrales corresponden al cruce sobre el encauzamiento de la ría de Avilés, mientras que los restantes, dispuestos simétricamente, salvan el cruce con líneas de ferrocarril y carreteras que circulan paralelamente a la ría.

Las pilas son rectas; y el tablero, correspondiente a una carretera de 20,50 m de ancho total, está dividido en dos por una junta longitudinal.

Cada semitablero apoya sobre cuatro vigas longitudinales.

La disposición longitudinal de cada viga es la siguiente: sobre el vano central de $17 \mathrm{~m}$ apoya una viga, con voladizos de $4 \mathrm{~m}$, en los que apoyan los dos tramos extremos, constituídos por vigas continuas apoyadas en las pilas por medio de péndulos.

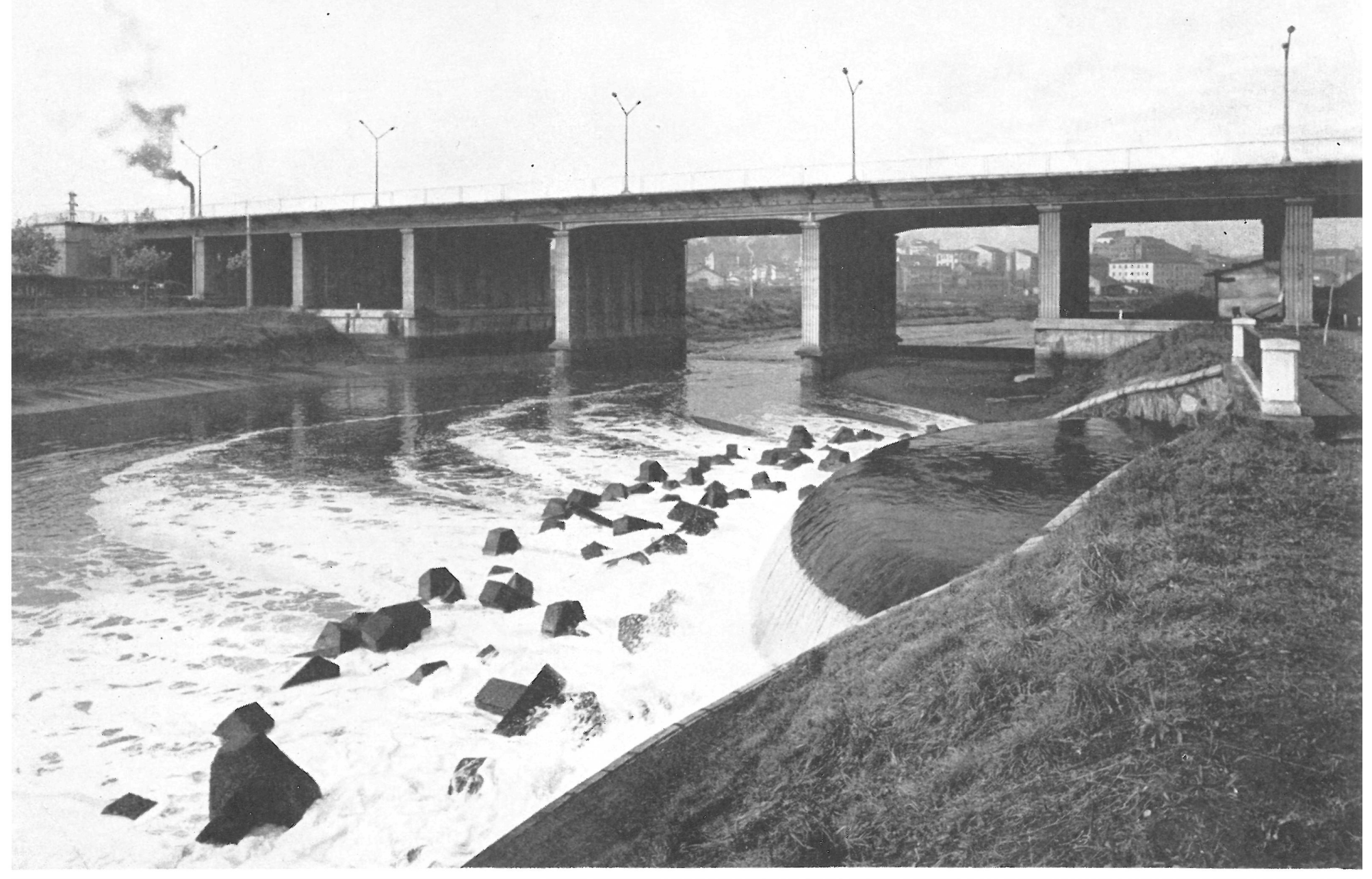

(c) Consejo Superior de Investigaciones Científicas Licencia Creative Commons 3.0 España (by-nc) 


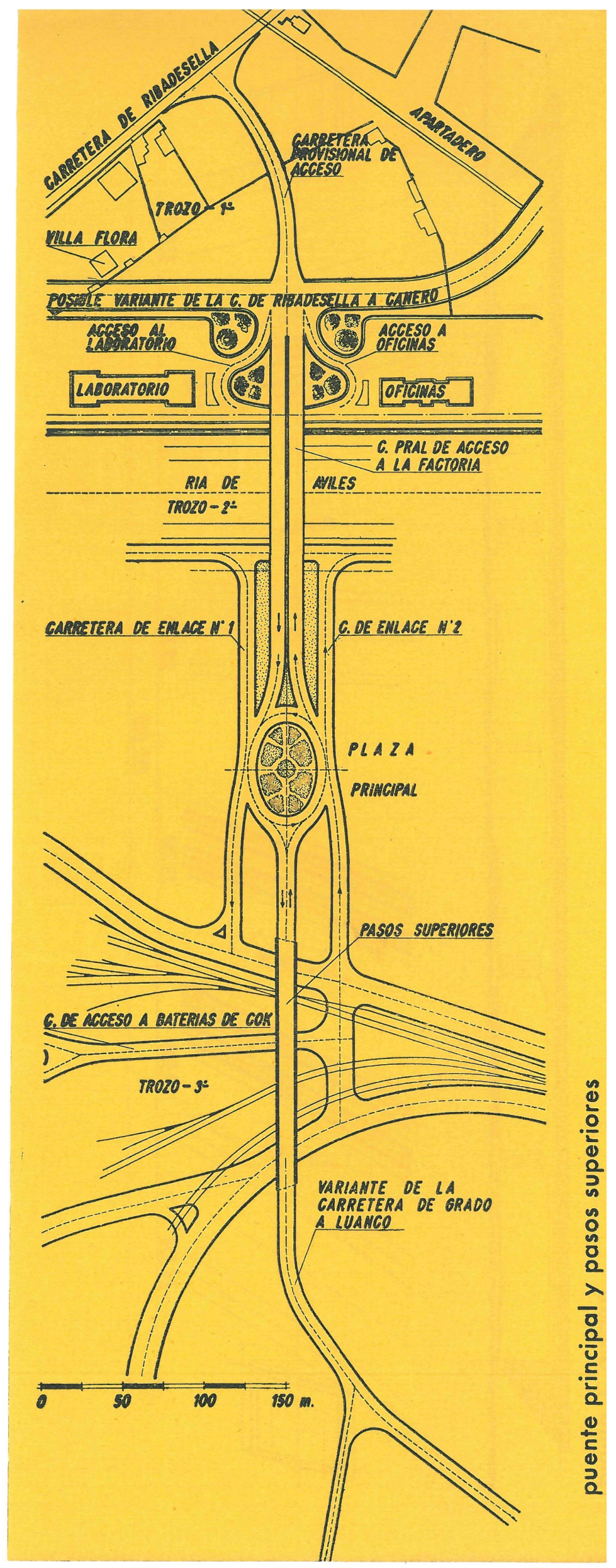




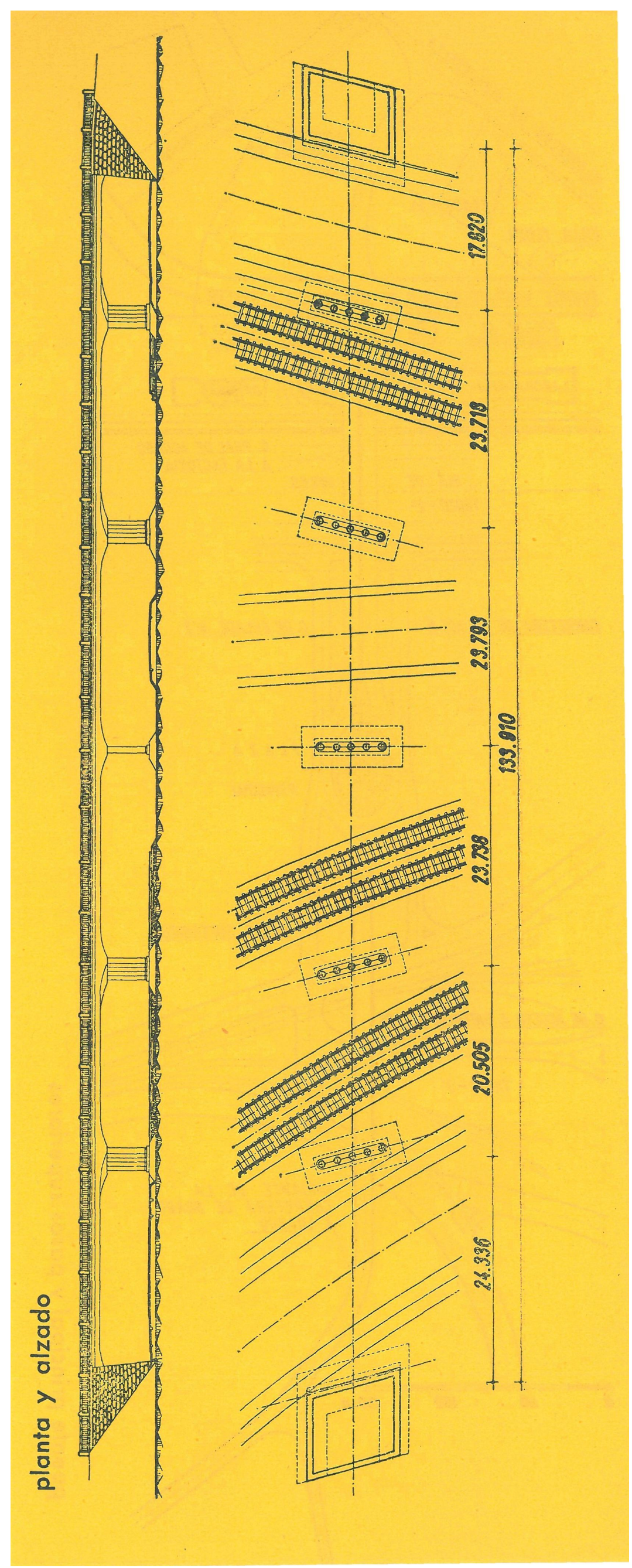




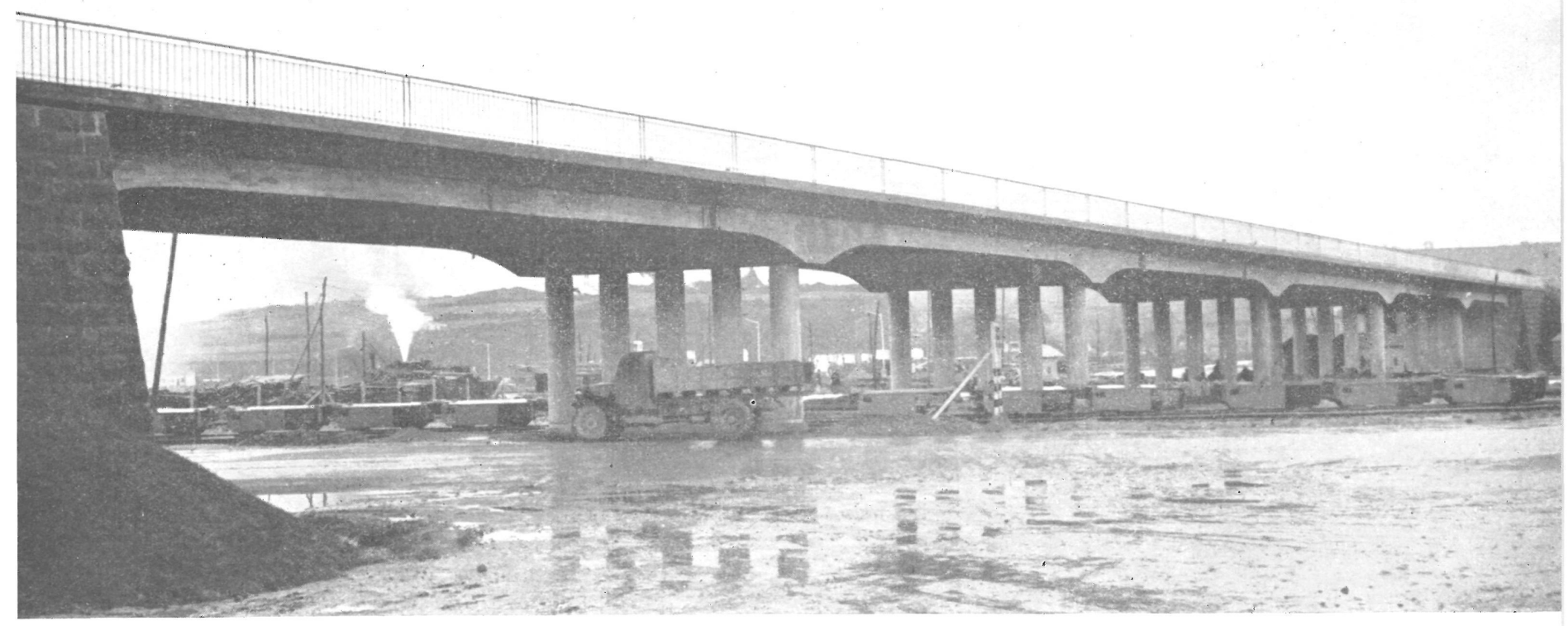

\section{pasos superiores}

En la variante de la carretera de Grado a Luanco, carretera que atraviesa la Factoría y que salva el cruce con vías y carreteras interiores, se ha construído un paso superior que consta de seis vanos, con luces variables comprendidas entre $17,820 \mathrm{~m}$ y $24,336 \mathrm{~m}$. Cada pila consta de cinco columnas cilíndricas en las que apoya el tablero.

Este tiene un ancho total de $10,70 \mathrm{~m}$ y la longitud de la obra entre estribos es de 133,910 metros. La cimentación de las pilas se hizo sobre pilotes, que en algunos casos no podrían llegar a alcanzar el firme a gran profundidad, y por este motivo se estudió un conjunto isostático, con rótulas y contrapesos, que permitiera absorber los pequeños asientos.

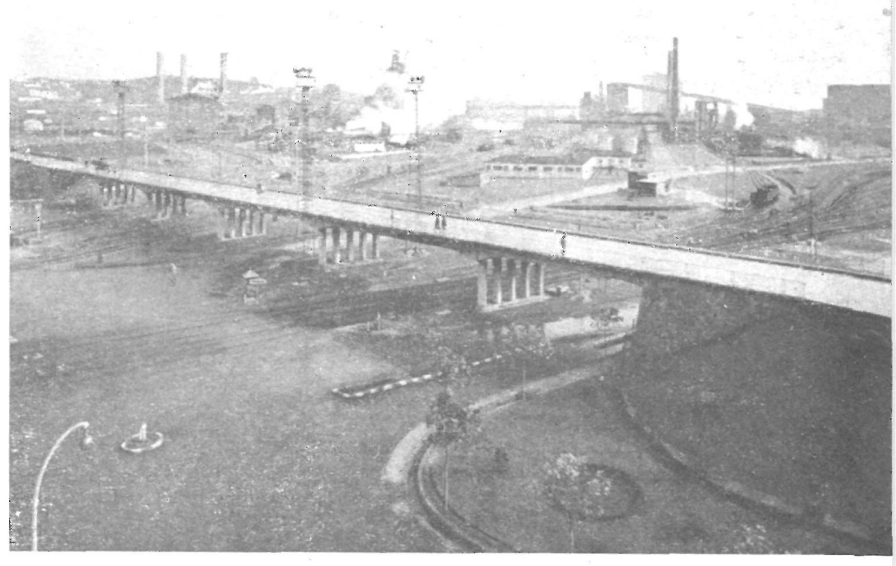




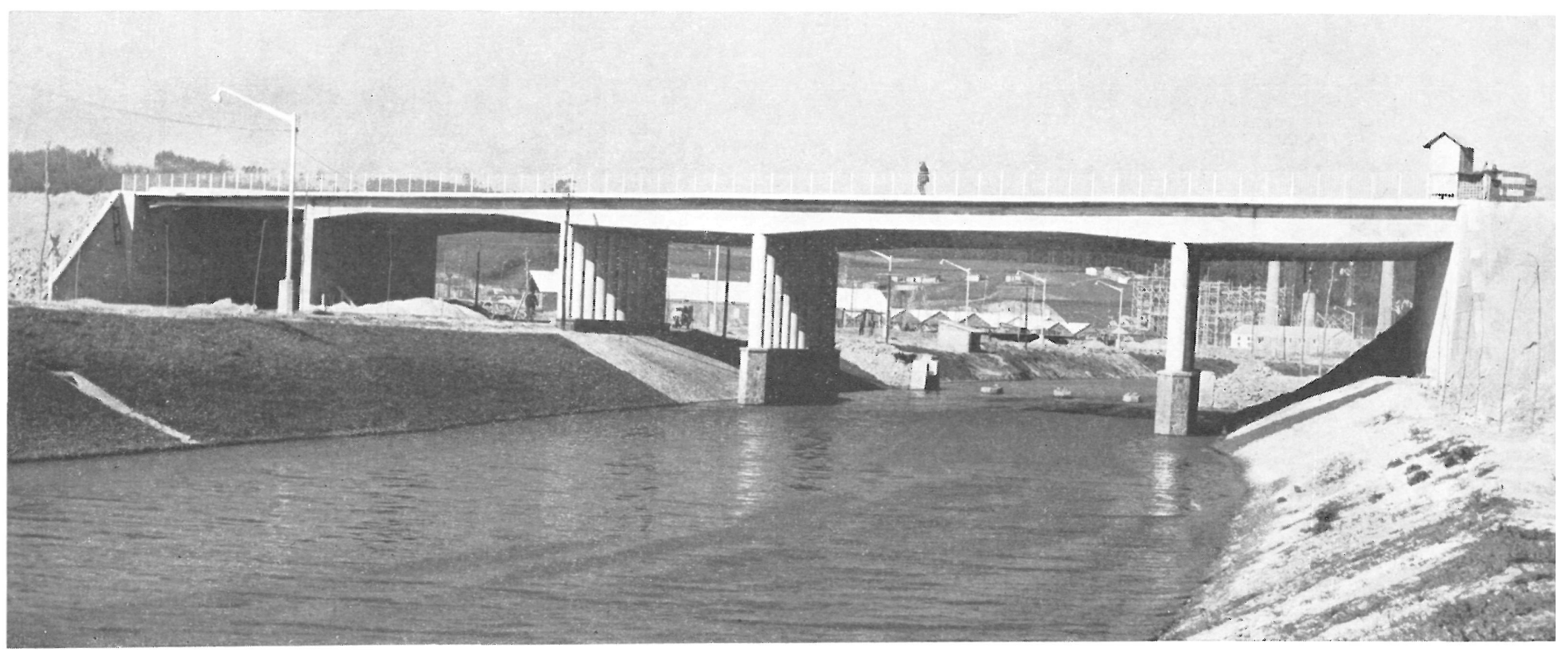

\section{puente de acceso por Llaranes}

Consta este puente de cinco vanos con luces entre 11 y $20 \mathrm{~m}$,

tres de los cuales constituyen puente sobre la ría y los dos restantes pasan, respectivamente,

sobre una carretera y una doble vía de ferrocarril del servicio interior de la fábrica.

Las pilas están formadas por grupos alineados de 10 columnas cilíndricas,

de $0,70 \mathrm{~m}$ de diámetro,

sobre las cuales apoyan las vigas longitudinales que soportan el tablero, el cual tiene una anchura total

de 20,50 m. Este puente es oblicuo, formando su eje un ángulo de 683

con el de la ría y las vías que salva.

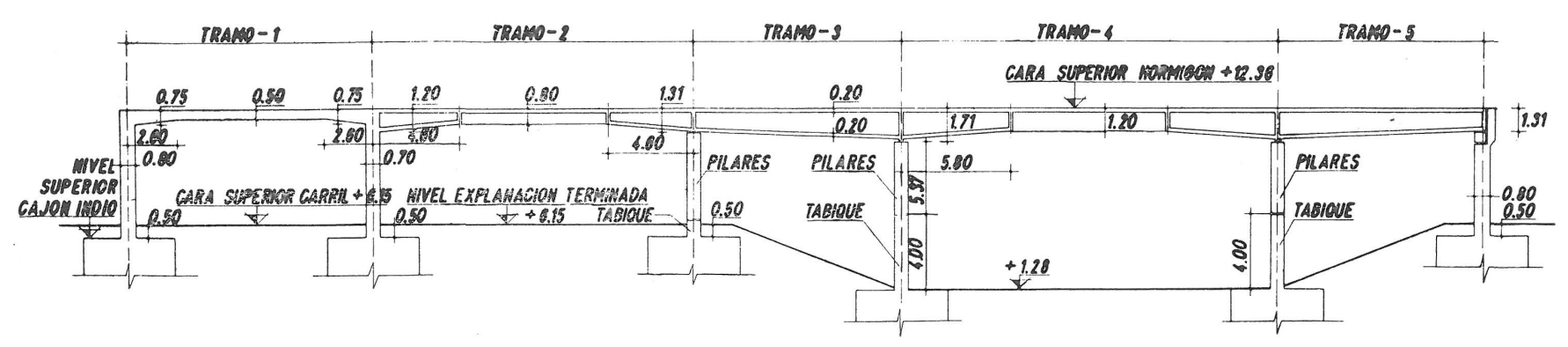

sección longitudinal 


\section{puente de acceso a talleres}

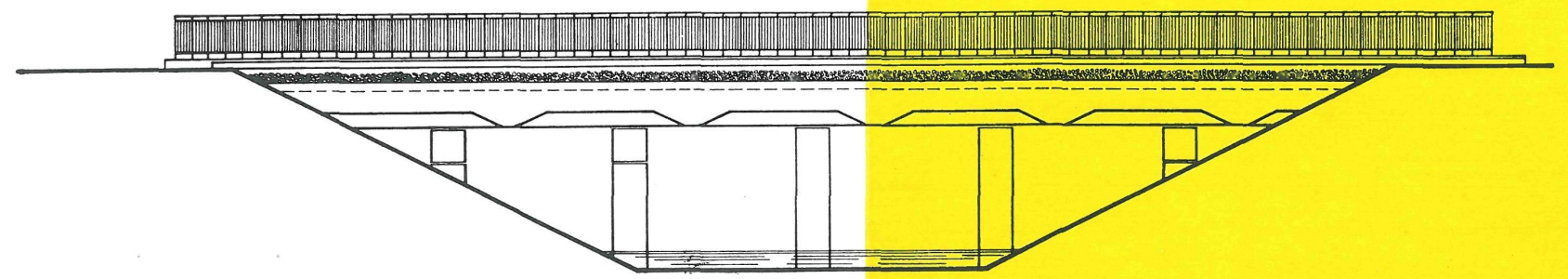

alzado

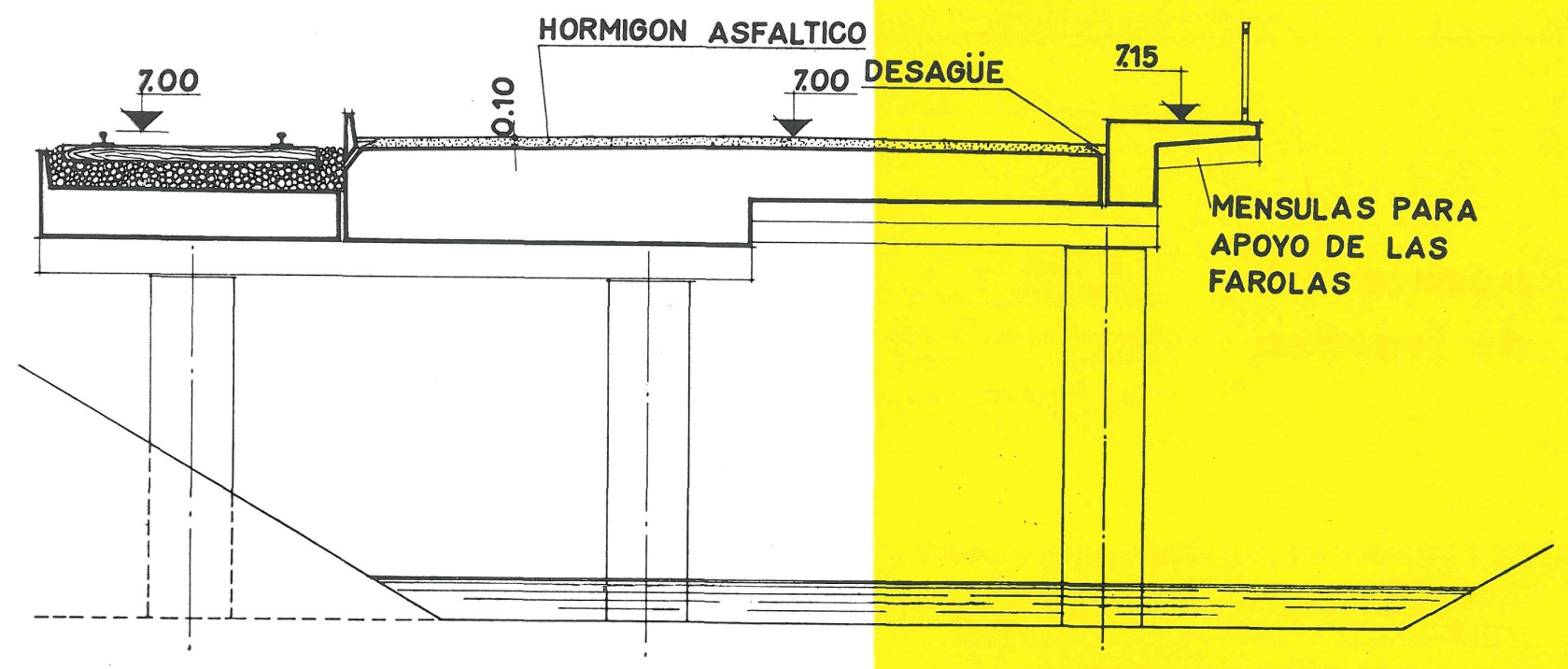

sección transversal

Salva la ría de Avilés, sirviendo de soporte a una carretera de $9 \mathrm{~m}$ de ancho y una vía de ferrocarril. Su tablero está constituído por una losa continua de hormigón armado apoyada sobre pilas cilíndricas, habiéndose suprimido las aletas o muros de acompañamiento. 


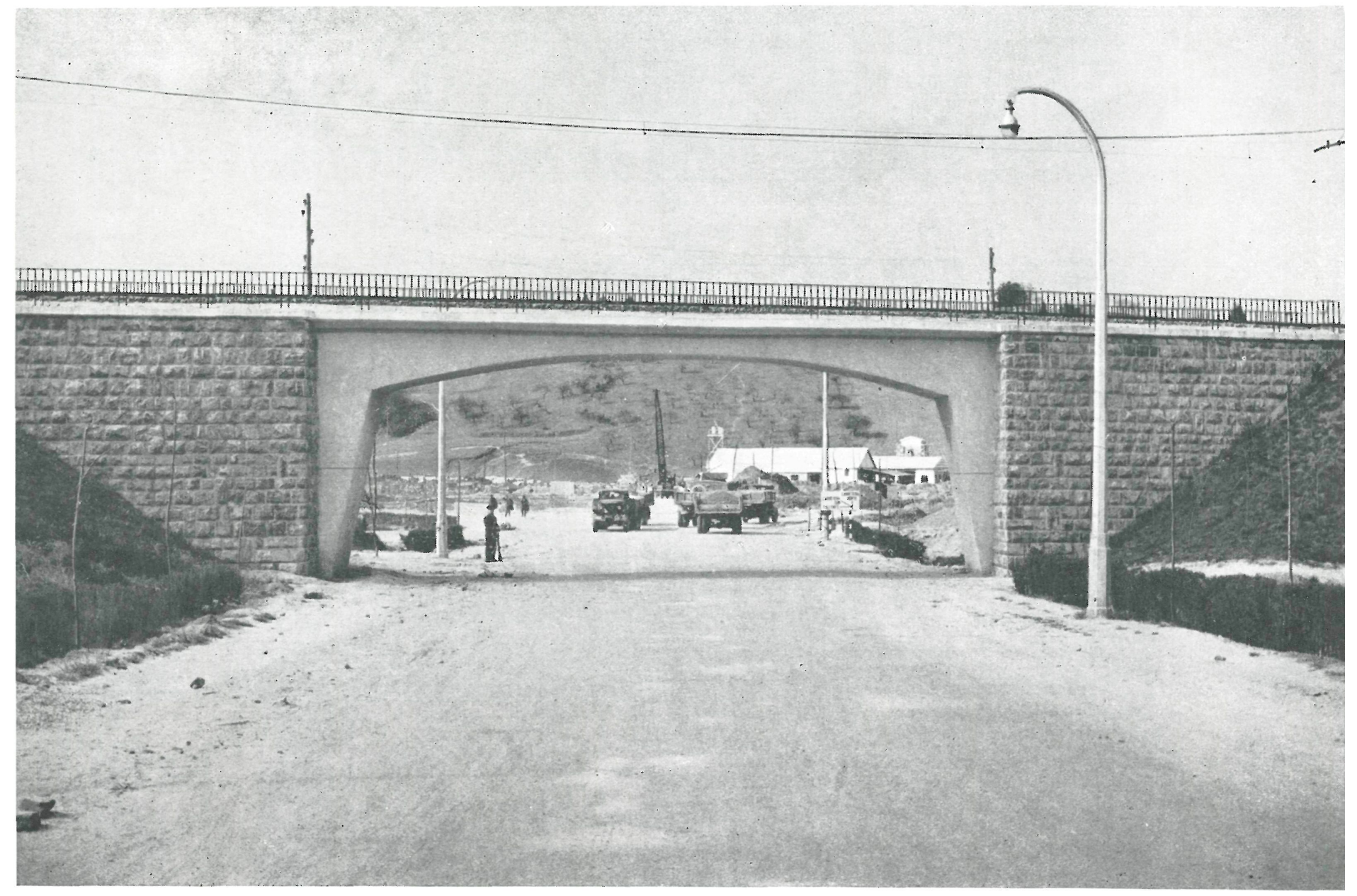

puente

de Trasona
El paso superior del F. C. Avilés-Gijón, de vía de $1 \mathrm{~m}$, sobre la carretera de acceso a la Factoría por Trasona, se ha resuelto con un puente oblicuo de $16 \mathrm{~m}$ de luz, formado con un pórtico de hormigón armado que lleva unidos los muros de acompañamiento del terraplén, triangulares, y que al actuar como contrapeso se consigue disminuir considerablemente los momentos en el centro del vano.

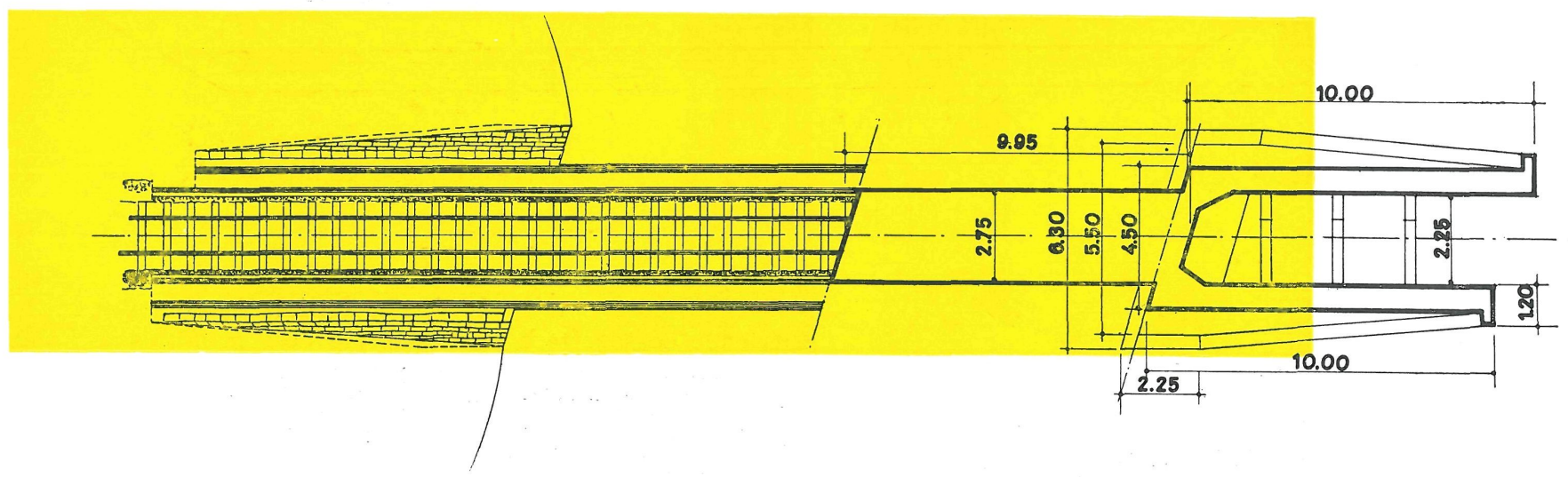

\section{pla $n+a$}




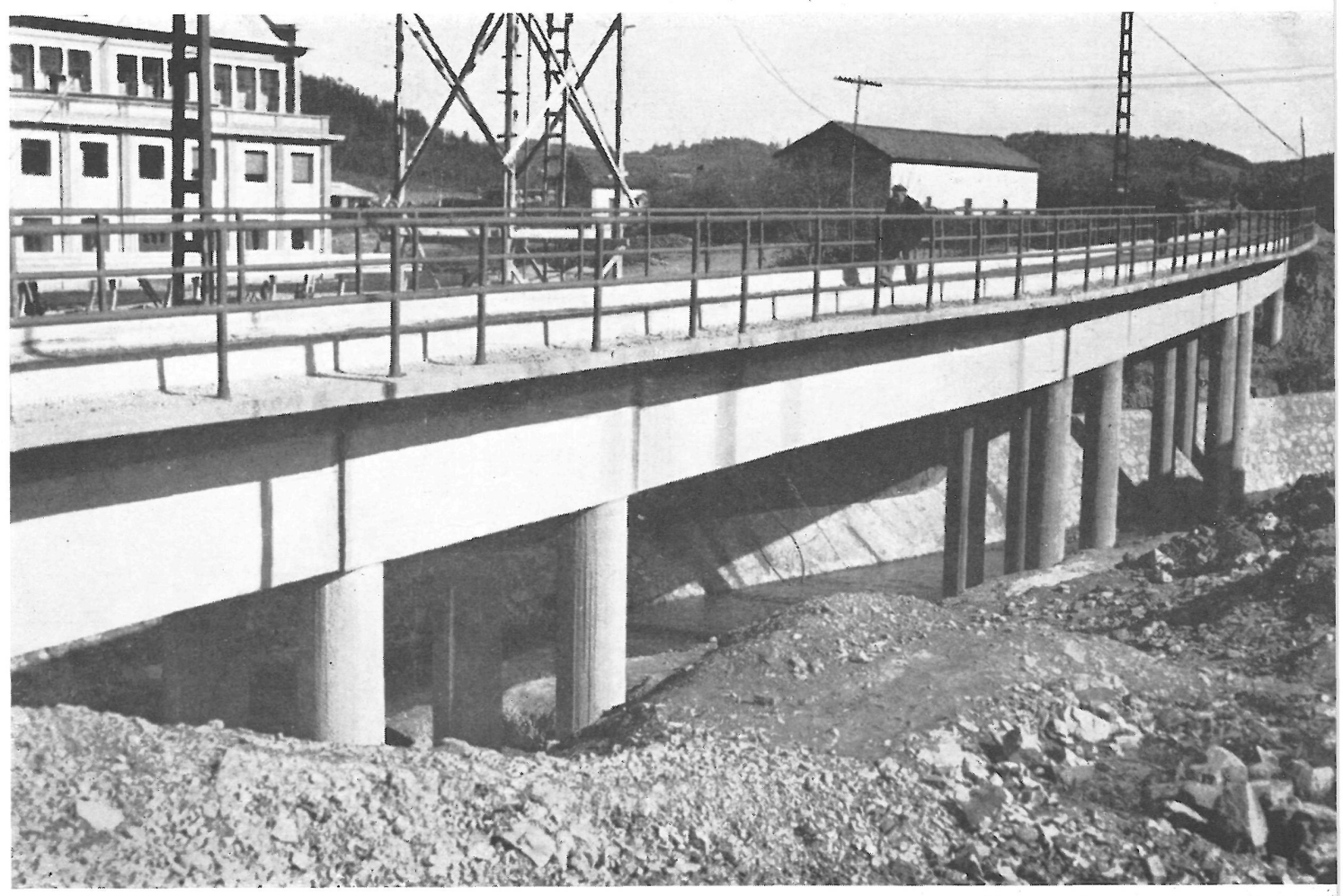

puente del ferrocarril Avilés - Gijón

Sobre el encauzamiento del río Corvera se ha construído un puente de planta poligonal que se adapta al trazado en curva de radio $300 \mathrm{~m}$ del F. C. El conjunto consta de cuatro vigas de $13 \mathrm{~m}$ de luz, habiendo entre cada dos de ellas un pórtico de 3,50 $\mathrm{m}$ entre ejes de pilas y terminando en los extremos con dos pórticos estribos de $3 \mathrm{~m}$ de luz. Los pórticos constan de cuatro columnas cilíndricas de $0,60 \mathrm{~m}$ de diámetro, empotradas en el cimiento, por lo que pueden considerarse como pilas aligeradas.

Puente sobre el encauzamiento del río comedores.

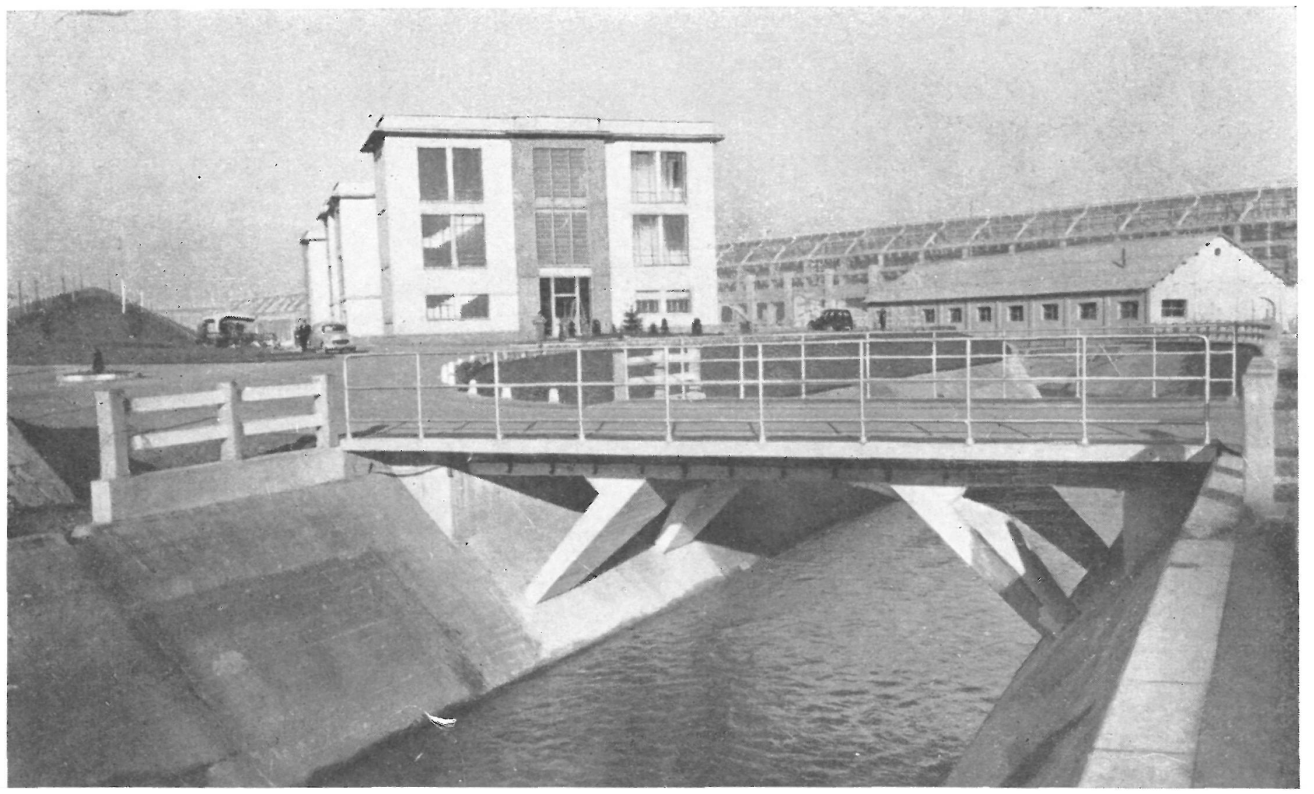



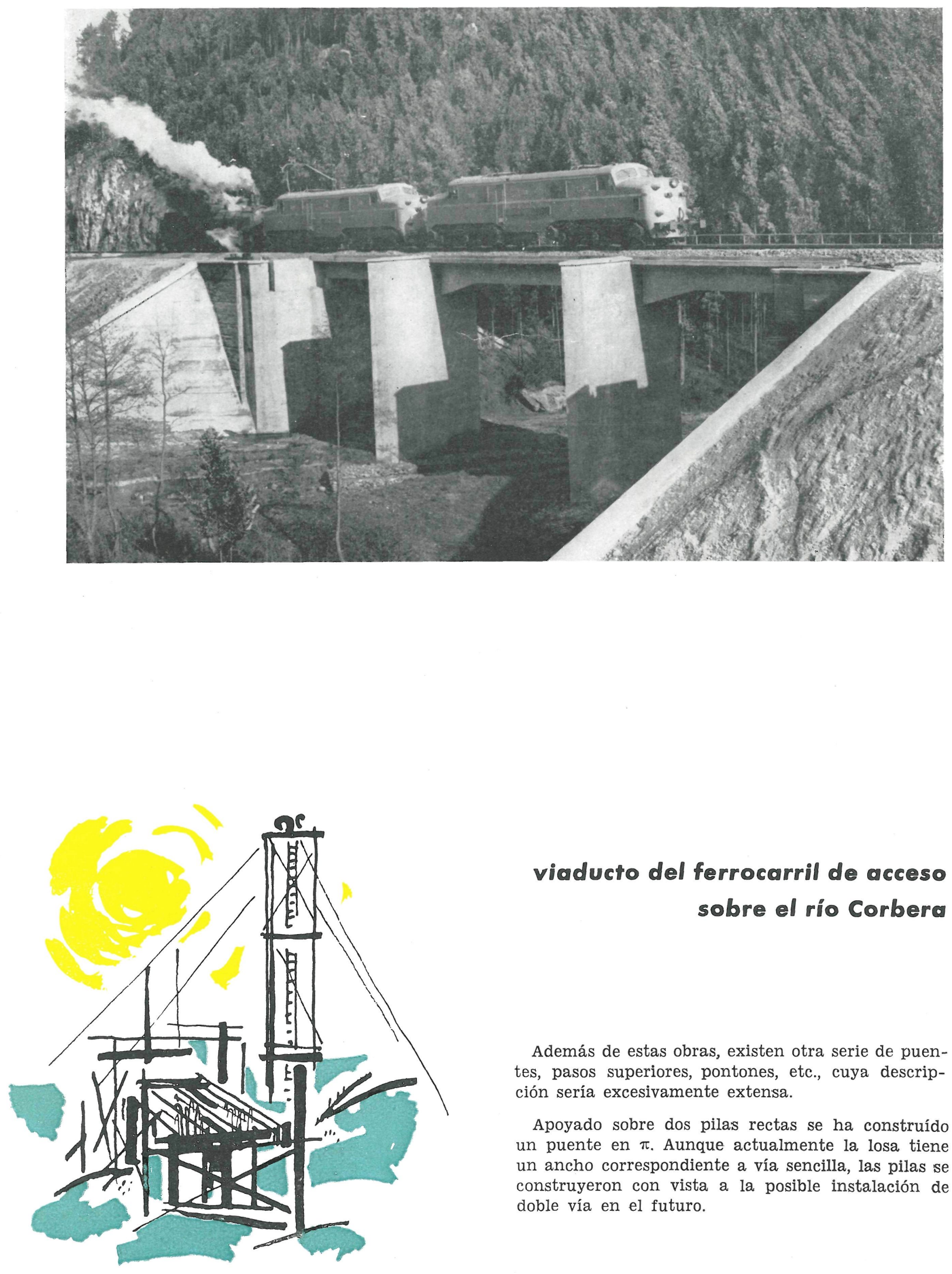

viaducto del ferrocarril de acceso sobre el río Corbera

Además de estas obras, existen otra serie de puentes, pasos superiores, pontones, etc., cuya descripción sería excesivamente extensa.

Apoyado sobre dos pilas rectas se ha construído un puente en $\pi$. Aunque actualmente la losa tiene un ancho correspondiente a vía sencilla, las pilas se construyeron con vista a la posible instalación de doble vía en el futuro. 